\title{
Associations of Transitional Zone Volume with Intraprostatic Chronic Inflammation and Prostate Cancer Risk in Patients Undergoing a First Random Biopsy Set
}

\author{
Antonio B. Porcaro ${ }^{\mathrm{a}} \quad$ Daniele Mattevi $^{\mathrm{a}} \quad$ Giovanni Novella $^{\mathrm{a}} \quad$ Nicolò De Luyk $^{\mathrm{a}}$ \\ Paolo Corsi $^{\mathrm{a}} \quad$ Leonardo Bizzotto $^{\mathrm{a}} \quad$ Davide De Marchi $^{\mathrm{a}} \quad$ Marco Sebben $^{\mathrm{a}}$ \\ Alessandro Tafuria ${ }^{a} \quad$ Davide Inverardia $^{a} \quad$ Tania Processali $^{a} \quad$ Maria A. Cerruto ${ }^{a}$ \\ Matteo Brunellib Salvatore Siracusano ${ }^{\mathrm{a}} \quad$ Walter Artibani $^{\mathrm{a}}$ \\ aUrologic Clinic; bepartment of Patholog, University Hospital, Ospedale Policlinico, \\ Azienda Ospedaliera Universitaria Integrata, Verona, Italy
}

\section{Key Words}

Prostate cancer $\cdot$ Chronic prostate inflammation •

Prostate-specific antigen - Prostate biopsy •

Prostate volume - Transitional zone volume

\begin{abstract}
Objectives: To investigate associations of the transitional zone volume (TZV) with intraprostatic chronic inflammatory infiltrate (CII) and prostate cancer (PCa) risk in patients undergoing a first random biopsy set. Materials and Methods: The study included a homogenous population of 596 patients. The volume of the prostate and TZV were separately measured. Independent associations were investigated by multivariate logistic regression analysis. Results: The median TZV was $18 \mathrm{ml}, \mathrm{Cll}$ was detected in 157 cases (26.3\%), and PCa was present in 292 patients (49\%). TZV was the only independent clinical factor associated with $\mathrm{Cll}$ risk $(\mathrm{OR}=1.014)$. After correcting for $\mathrm{CII}(\mathrm{OR}=0.276 ; \mathrm{p}<0.0001)$, independent factors associated with PCa risk included age $(O R=1.066)$, prostate specific antigen $(O R=1.177), T Z V(O R=0.919)$, and an abnormal digital rectal exam $(\mathrm{OR}=2.024)$. Conclusion: In a patient population undergoing a first random prostate
\end{abstract}

\section{KARGER}

(C) 2017 S. Karger AG, Basel

Fax +4161306 1234

E-Mail karger@karger.com

www.karger.com
Accessible online at: www.karger.com/cur biopsy set because of suspected cancer, independent associations were detected among TZV, CII, and PCa. The association between TZV and CII was direct, but the relation between TZV and PCa was inverse. The measurement of the volume of the transitional zone was a useful parameter for evaluating chronic intraprostatic inflammation and PCa risk.

Copyright $\odot 2017$ S. Karger AG, Basel

\section{Introduction}

In clinical practice, the zonal anatomy of the prostate is important in assessing the origin and location of disorders affecting the gland [1]. Benign prostate hyperplasia $(\mathrm{BPH})$ and prostate cancer $(\mathrm{PCa})$ represent the two main growth disorders. The former develops in the transition zone while the latter in the peripheral part of the gland.

The measurement of prostate volume (PV) is important when considering medical and surgical treatments of both BPH and PCa. Moreover, measurements of volumes of the prostate zonal anatomy are even more important 
because they are related to the development of both BPH and $\mathrm{PCa}$ which are independent from each other and do not show any causal association [1-3]. When considering BPH pathophysiology, it is important to evaluate the transitional zone volume (TZV) because its variations relate to the anatomy of the aging prostate. It is also important to evaluate the volume and anatomy of the peripheral zone when assessing PCa.

The prostate may also be affected by inflammatory disorders. Clinically, the prostatitis syndromes have been classified into 4 categories by the National Institutes of Health [4]. The last category, type IV, is diagnosed in patients who have no history of genitourinary tract pain complaints, but undergo prostate biopsy for evaluation of possible $\mathrm{PCa}$ because of an increased serum prostate-specific antigen (PSA) level, abnormal digital rectal exam (DRE) or both. In biopsy cores, histology shows the presence of chronic inflammatory infiltrate (CII) that might associate with both PCa and/or BPH $[5,6]$. The nature of the association between CII and PCa represents a controversial subject that is still unsettled.

We have shown that there is a negative association between chronic inflammation and PCa risk in patients undergoing biopsy because of suspected cancer [7, 8]. We have also demonstrated that the relations between TZV and the peripheral zone volume (PZV) play an important role in evaluating the risk of detecting $\mathrm{PCa}$ in patients electing a first random biopsy set [7, 9]. In addition, we have shown that the ratio of TZV and PZV, and the prostate volume (PV) index are associated with a decreased risk of detecting PCa. The aim of the present study was to investigate associations of TZV with chronic inflammation and $\mathrm{PCa}$ risk in patients electing a first random biopsy set.

\section{Materials and Methods}

Collection and use of patient data had Institutional Board Review approval. All patients signed informed consent for using the data. The study was retrospective and evaluated the records of 1,327 patients who underwent prostate biopsy in the period ranging from September 2010 to September 2015. The exclusion criteria were as follows: (i) repeat biopsy $(68.5 \%)$, (ii) active surveillance (15\%), (iii) previous BPH surgery (3.7\%), (iv) medical treatment with inhibitors of enzyme 5-alpha reductase $(3.7 \%)$, or (v) biopsy samples of less than 14 cores $(9.1 \%)$. In the design of the study, patients having biopsy samples less than 14 cores were excluded in order to evaluate a homogenous patient population undergoing a first set of random biopsies. As a result, the study excluded 731 cases. The analysis deliberately excluded additional targeted cores in order to avoid a skewed phenomenon. According to the aim of the study, additional targeted cores were ignored in order to assess a homogenous population. Biopsy indications were as follows: (i) increased PSA levels (73.7\%), (ii) abnormal DRE findings $(4.76 \%)$, (iii) abnormal DRE with increased PSA levels (14.9\%), and (iv) abnormal imaging findings (6.5\%).

In each patient, measurements included age (years), body mass index (BMI, $\left.\mathrm{kg} / \mathrm{m}^{2}\right)$, levels of PSA $(\mu \mathrm{g} / \mathrm{l})$, PV $(\mathrm{ml})$, PSA density (PSAD, $\mu \mathrm{g} / \mathrm{l} / \mathrm{ml}$ ), and DRE findings (normal, abnormal). PV was measured by transrectal ultrasound (TRUS) and was determined by using the formula for the ellipsoid that was transformed into volume $(\mathrm{ml})$. The TZV was measured in the same fashion. Moreover, measurement of the TZV also included an evaluation of the median lobe volume when present $[7,9]$. PV and TZV were separately measured and PZV was determined by subtracting PV from TZV. The random 14-core TRUS-guided prostate biopsy was routinely performed by the trans-perineum technique [7, 9]. For each core, a dedicated pathologist systematically assessed the following issues: (i) length, (ii) PCa and its grade according to the new tumor prognostic grading system related to biopsy Gleason score and pattern [10-12], (iii) percentage of cancer involving the core, (iv) prostatic intraepithelial neoplasia, (v) CII, (vi) glandular atrophy, and (vii) atypical small acinar cell proliferation. Chronic inflammation criteria, which have already been reported [7, 8], included inflammatory cell infiltrates composed predominantly of lymphocytes associated with admixed plasma cells showing a peri-glandular distribution pattern. Sheets of neutrophils around and within the glands as well as aspects of granulomatous prostatitis were excluding criteria.

\section{Statistical Design and Methods}

The population was first clustered in 2 groups by the presence or absence of CII in order to assess associated clinical factors. Patients were then grouped in cases with or without PCa with the aim of evaluating associated clinical factors. Data on continuous variables are reported as medians with their respective ranges and differences between groups were analyzed with the Mann-Whitney test. Data on categorical variables are presented as proportions, and differences between groups were analyzed with Pearson's chi-squared test or Fisher exact test as appropriate.

The multivariate logistic regression model assessed independent factors associated with CII and PCa risk. The mean probability logistic regression model was computed after assessing independent predictive variables. The goodness of fit of the final model was assessed by the Hosmer-Lemeshow test, which assesses the model by the deciles of risk grouping strategy of the estimated probabilities generated by the model. Finally, clinical probability risk models predicting $\mathrm{CII}$ and $\mathrm{PCa}$ were computed. The software used to run the analysis was IBM-SPSS version 20. All tests were two-sided, with a significance level of $\mathrm{p}<0.05$.

\section{Results}

The statistical summary of the evaluated cohort (n $=596$ ) is reported in table 1 . The median volume of the transitional zone was $18 \mathrm{ml}$, CII was detected in 157 cases $(26.3 \%)$, and $\mathrm{PCa}$ was present in 292 patients (49 $\%)$. 
Table 1. Demographics of the patient population $(n=596)$ undergoing a first biopsy set

\begin{tabular}{|c|c|c|}
\hline Variables & Median (range) & $\mathrm{n}(\%)$ \\
\hline Age, year & $67.0(40-90)$ & \\
\hline BMI, kg/m² & $26.1(18.2-42.6)$ & \\
\hline PSA, $\mu \mathrm{g} / \mathrm{l}$ & $6.2(0.3-524)$ & \\
\hline $\mathrm{PV}, \mathrm{ml}$ & $38.2(9.2-182.8)$ & \\
\hline $\mathrm{TZV}, \mathrm{ml}$ & $18.0(2.0-112.5)$ & \\
\hline PSAD, $\mu \mathrm{g} / \mathrm{l} / \mathrm{ml}$ & $0.16(0.01-106.2)$ & \\
\hline $\mathrm{L}, \mathrm{mm}$ & $15.4(10-40)$ & \\
\hline \multicolumn{3}{|l|}{ DRE } \\
\hline Normal & & $425(71.3 \%)$ \\
\hline Abnormal & & $171(28.7 \%)$ \\
\hline \multicolumn{3}{|l|}{$\mathrm{PCa}$} \\
\hline No & & $304(51.0 \%)$ \\
\hline Yes & & $292(49.0 \%)$ \\
\hline \multicolumn{3}{|l|}{ CII } \\
\hline No & & $438(73.7 \%)$ \\
\hline Yes & & $157(26.3 \%)$ \\
\hline \multicolumn{3}{|l|}{ BGS } \\
\hline 6 & & $151(51.7 \%)$ \\
\hline 7 & & $101(34.6 \%)$ \\
\hline$>7$ & & $40(13.7 \%)$ \\
\hline
\end{tabular}

$\mathrm{BMI}=$ Body mass index $; \mathrm{L}=$ length of the biopsy core; $\mathrm{BGS}=$ biopsy Gleason score.
Table 2. Cross-classification of factors associated with intraprostatic CII in patients undergoing a first biopsy set $(n=596)$

\begin{tabular}{lccl}
\hline Variables & \multicolumn{2}{c}{ CII } & $\mathrm{p}$ \\
\cline { 2 - 3 } & No & Yes & 0.682 \\
\hline $\begin{array}{l}\text { PSA, } \mu \mathrm{g} / \mathrm{l} \\
\text { median (range) }\end{array}$ & $6.1(0.26-465)$ & $6.2(0.90-524.45)$ & 0.002 \\
$\begin{array}{l}\text { PV, ml } \\
\text { median (range) }\end{array}$ & $36.7(11.2-180.9)$ & $44.6(9.2-182.8)$ & \\
$\begin{array}{l}\text { TZV, ml } \\
\text { median (range) }\end{array}$ & $17.2(2-112.5)$ & $22.8(4.6-76.9)$ & $<0.00001$ \\
$\begin{array}{l}\text { PSAD, } \mu \mathrm{g} / \mathrm{l} / \mathrm{ml} \\
\text { median (range) }\end{array}$ & $0.16(0.01-6.90)$ & $0.15(0.01-27.8)$ & 0.008 \\
$\begin{array}{l}\text { DRE, } \mathrm{n}(\%) \\
\quad \begin{array}{l}\text { Normal } \\
\text { Abnormal }\end{array}\end{array}$ & $312(71.1 \%)$ & $113(72.0 \%)$ & 0.830 \\
$\begin{array}{l}\text { PCa, n (\%) } \\
\quad \text { No }\end{array}$ & $188(28.9 \%)$ & $44(28.0 \%)$ & \\
$\quad$ Yes & $251(57.2 \%)$ & $116(73.9 \%)$ & $<0.0001$ \\
\hline
\end{tabular}

Association between TZV and CII in patients undergoing first random biopsy set because of suspected cancer. The probability of detecting CII in the biopsy cores is directly associated with increasing measurements of TZV.

Table 3. Multivariate logistic regression analysis of factors associated with the risk of chronic intraprostatic inflammation in patients undergoing a first biopsy set $(n=596)$

\begin{tabular}{|c|c|c|c|c|c|c|}
\hline \multirow[t]{2}{*}{ Factors } & \multicolumn{3}{|c|}{ Model A } & \multicolumn{3}{|c|}{ Model B } \\
\hline & OR & $95 \% \mathrm{CI}$ of OR & $\mathrm{p}$ & OR & $95 \% \mathrm{CI}$ of OR & $\mathrm{p}$ \\
\hline PV & 0.985 & $0.960-1.012$ & 0.275 & & & \\
\hline $\mathrm{TZV}$ & 1.036 & $0.996-1.078$ & 0.078 & 1.014 & $1.001-1.028$ & 0.039 \\
\hline PSAD & 1.122 & $0.958-1.134$ & 0.153 & & & \\
\hline $\mathrm{PCa}$ & 0.290 & $0.189-0.445$ & $<0.0001$ & 0.300 & $0.197-0.457$ & $<0.0001$ \\
\hline
\end{tabular}
$\mathrm{PCa}$

Model A: model including all significant variables in the univariate analysis; Model B: model after removing not significant variables and correcting

The cross-classification of clinical factors with CII is shown in table 2. Intraprostatic CII was associated with $\mathrm{PV}, \mathrm{TZV}$, and PSAD and there was an inverse association between PCa and CII.

Multivariate logistic regression analysis (table 3) showed that TZV was an independent factor associated with chronic intraprostatic inflammation $(\mathrm{OR}=1.014$, 95\% CI: 1.001-1.028, $\mathrm{p}=0.039$ ) after removing confounders (PV and PSAD) and correcting PCa (OR = 0.300, 95\%CI: $0.97-0.457, \mathrm{p}<0.0001)$. Figure 1 shows the probability model of detecting CII in the biopsy cores by TZV measurements.

Age, PSA, PV, TZV, PSAD, abnormal DRE, and CII were associated with PCa (table 4). The association between factors and PCa was direct for age, PSA, PSAD, and abnormal DRE, but inverse for PV, TZV, and CII. The multivariate model showed that age $(\mathrm{OR}=1.066$, 95\% CI: $1.039-1.093, \mathrm{p}<0.0001)$, PSA (OR $=1.177$, 95\% CI: $1.108-1.251, \mathrm{p}<0.0001)$, TZV $(\mathrm{OR}=0.919$, 95\%CI: 0.901-0.938, p < 0.0001), abnormal DRE (OR 
Table 4. Cross-classification of factors associated with PCa in the patient population $(\mathrm{n}=596)$

\begin{tabular}{|c|c|c|c|}
\hline \multirow[t]{2}{*}{ Variables } & \multicolumn{2}{|c|}{$\mathrm{PCa}$} & \multirow[t]{2}{*}{ Range } \\
\hline & No $(n=304,51 \%)$ & Yes $(n=292,49 \%)$ & \\
\hline Age, year & & & $<0.0001$ \\
\hline median (range) & $65.0(42-90)$ & $68.5(40-90)$ & \\
\hline BMI, $\mathrm{kg} / \mathrm{m}^{2}$ & & & 0.253 \\
\hline median (range) & $26.0(18.3-42.6)$ & $26.1(18.2-39.1)$ & \\
\hline PSA, $\mu \mathrm{g} / 1$ & & & $<0.0001$ \\
\hline median (range) & $6.03(0.3-26)$ & $6.28(1-524)$ & \\
\hline $\begin{array}{l}\mathrm{PV}, \mathrm{ml} \\
\text { median (range) }\end{array}$ & $44.1(9.2-180.9)$ & $32.3(12.2-182.4)$ & $<0.0001$ \\
\hline $\mathrm{TZV}, \mathrm{ml}$ & & & $<0.0001$ \\
\hline median (range) & $23.2(4-12.5)$ & $14.6(2-76.9)$ & \\
\hline PSAD, $\mu \mathrm{g} / \mathrm{l} / \mathrm{ml}$ & & & $<0.0001$ \\
\hline median (range) & $0.13(0.01-0.73)$ & $0.20(0.02-27.8)$ & \\
\hline DRE, n (\%) & & & $<0.0001$ \\
\hline Normal & 243 (79.9) & $182(62.3)$ & \\
\hline Abnormal & $61(20.1)$ & $110(37.7)$ & \\
\hline CII, n (\%) & & & $<0.0001$ \\
\hline No & $188(61.8)$ & $251(86.0)$ & \\
\hline Yes & $116(38.2)$ & $41(14.0)$ & \\
\hline
\end{tabular}

BMI $=$ Body mass index

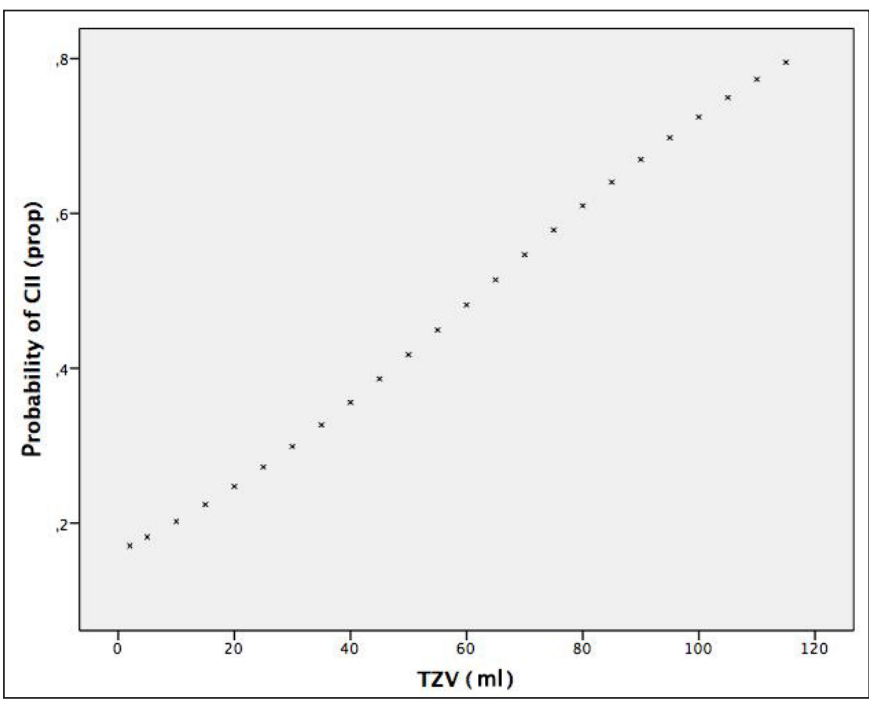

Fig. 1. Association between TZV and CII in patients undergoing the first random biopsy set because of suspected cancer. The probability of detecting CII in the biopsy cores is directly associated with increasing measurements of TZV.

Table 5. Multivariate logistic regression analysis of factors associated with PCa risk in the population of patients undergoing a first random biopsy set $(\mathrm{n}=596)$

\begin{tabular}{|c|c|c|c|c|c|c|}
\hline \multirow[t]{2}{*}{ Factors } & \multicolumn{3}{|c|}{ Model A } & \multicolumn{3}{|c|}{ Model B } \\
\hline & OR & $95 \% \mathrm{CI}$ of OR & $\mathrm{p}$ & OR & $95 \% \mathrm{CI}$ of OR & $\mathrm{p}$ \\
\hline Age & 1.066 & $1.038-1.093$ & $<0.0001$ & 1.066 & $1.039-1.093$ & $<0.0001$ \\
\hline PSA & 1.056 & $0.933-1.195$ & 0.388 & 1.177 & $1.108-1.251$ & $<0.0001$ \\
\hline PV & 1.023 & $0.986-1.061$ & 0.233 & & & \\
\hline $\mathrm{TZV}$ & 0.916 & $0.872-0.962$ & $<0.0001$ & 0.919 & $0.901-0.938$ & $<0.0001$ \\
\hline PSAD & 6.546 & $0.827-9152.472$ & 0.060 & & & \\
\hline CII & 0.271 & $0.170-0.433$ & $<0.0001$ & 0.276 & $0.174-0.439$ & $<0.0001$ \\
\hline DRE & 2.316 & $1.478-3.628$ & $<0.0001$ & 2.024 & $1.415-3.428$ & $<0.0001$ \\
\hline
\end{tabular}

Model A: model including all significant variables in the univariate analysis, Model B: model after removing not significant variables and correcting intraprostatic CII.

Table 6. Multivariate logistic regression model of clinical factors predicting $\mathrm{PCa}$ risk stratified by TZV in patients undergoing a first random biopsy set $(\mathrm{n}=596)$

\begin{tabular}{llll}
\hline Factors & OR & $95 \% \mathrm{CI}$ of OR & $\mathrm{p}$ \\
\hline Age & 1.059 & $1.033-1.085$ & $<0.0001$ \\
PSA & 1.147 & $1.088-1.210$ & $<0.0001$ \\
TZV $(1)^{*}$ & 0.476 & $0.284-0.799$ & 0.005 \\
TZV $(2)^{*}$ & 0.214 & $0.126-0.364$ & $<0.0001$ \\
TZV $(3)^{*}$ & 0.064 & $0.035-0.119$ & $<0.0001$ \\
DRE $^{* *}$ & 2.134 & $1.394-3.266$ & $<0.0001$ \\
\hline
\end{tabular}

TZV (1), TZV first quartile (TZV $\leq 12.3 \mathrm{ml}) ; \mathrm{TZV}(2), \mathrm{TZV}$ second quartile (12.3 $<\mathrm{TZV} \leq 18.0 \mathrm{ml})$; TZV (3); TZV third quartile $(18.0<\mathrm{TZV} \leq 27.7 \mathrm{ml})$; TZV (4), TZV fourth quartile $(27.7<\mathrm{TZV} \leq 112.5 \mathrm{ml}) ;{ }^{*}$ reference TZV $(4) ;{ }^{* *}$ reference normal DRE.
$=2.024,95 \% \mathrm{CI}: 1.415-3.428, \mathrm{p}<0.0001)$, and CII were independent predictors of $\mathrm{PCa}$ (table 5). The volume of the transitional zone and the presence of chronic intraprostatic inflammation were independently associated with a reduced risk of $\mathrm{PCa}$.

The volume of the transitional zone was categorized by quartiles as follows: (i) first quartile: $\mathrm{TZV} \leq 12.3 \mathrm{ml}$ ), (ii) second quartile: $12.3<\mathrm{TZV} \leq 18.0 \mathrm{ml}$, (iii) third quartile: $18.0<\mathrm{TZV} \leq 27.7 \mathrm{ml}$ ), and (iv) fourth quartile: $27.7<\mathrm{TZV} \leq 112.5 \mathrm{ml}$. The fourth quartile was the reference category. The final model showed that age, PSA, and categorized TZV were independent clinical predictors of PCa risk (table 6). The Hosmer-Lemeshow test assessed the efficacy of the model (Chi squared $=5.435$, $\mathrm{p}=0.710)$. 


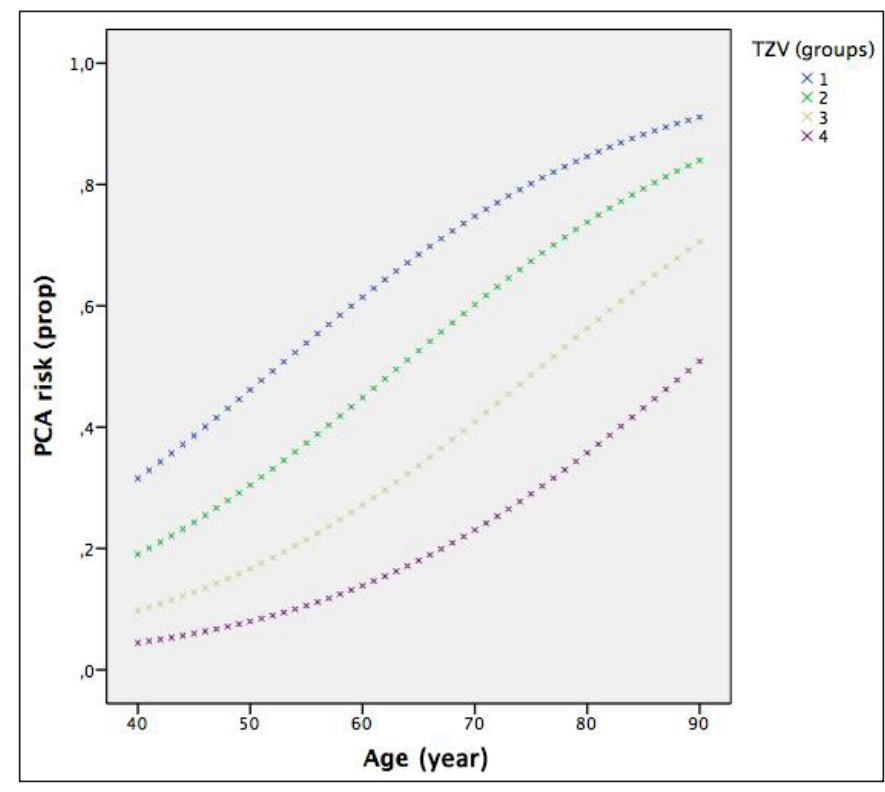

Fig. 2. Association of TZV and age with PCa risk in patients electing a first random biopsy set. The probability of $\mathrm{PCa}$ is directly associated with age. However, when we stratified the population into 4 groups of increasing TZV quartiles, the risk of PCa was decreased at the same age levels because of the inverse association between TZV and PCa. The patient population was clustered in 4 groups according to ranking TZV quartiles as follows: (i) group 1: TZV within the first quartile, (ii) group 2: TZV above the first quartile but within the median (second quartile), (iii) group 3: TZV above the median and within the third quartile, and (iv) group 4: TZV above the third quartile.

PCa risk models including age and PSA with categorized TZV (normal DRE) are shown in figure 2 and 3. The PCa model predicted by TZV and stratified by chronic intraprostatic inflammation is depicted in figure 4.

\section{Discussion}

The present investigation showed that TZV was associated with $\mathrm{CII}$ in patients electing a first random biopsy set because of suspected cancer. The probability of detecting $\mathrm{CII}$ in the biopsy cores was directly related to increasing measurements of TZV (see fig. 1). This study showed associations between chronic intraprostatic inflammation and growth of the transitional zone. The relationships between chronic inflammation and BPH are controversial $[2,3]$ and our study brings new evidence to this subject.

Transitional Zone Volume, Chronic Intraprostatic Inflammation, and Prostate Cancer Risk

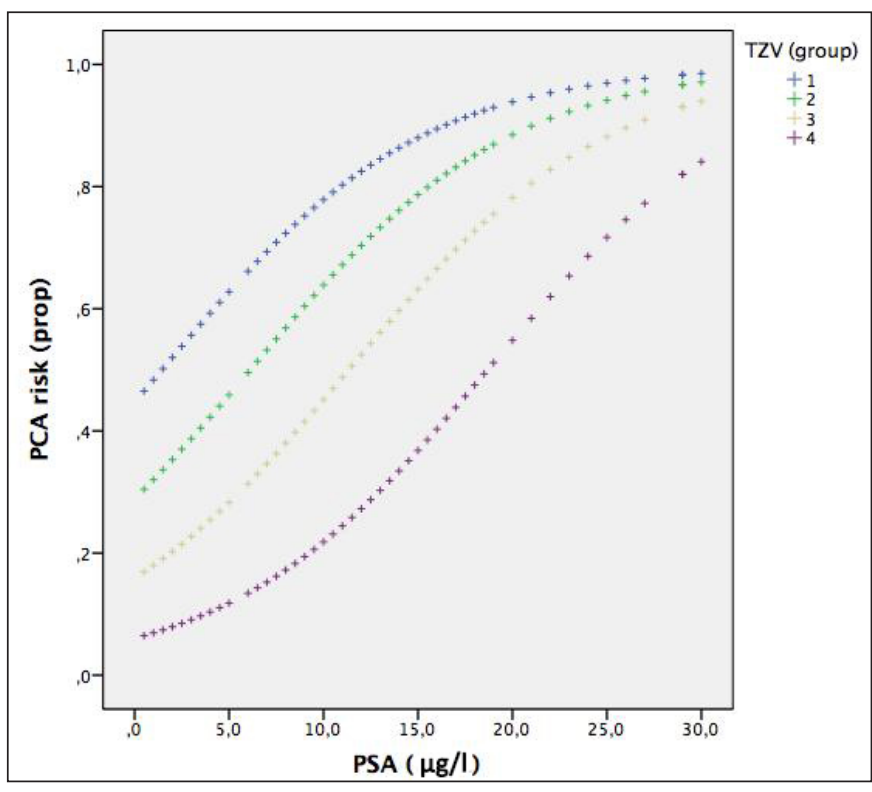

Fig. 3. Association of TZV and PSA with PCa risk in patients electing a first random biopsy set. The probability of $\mathrm{PCa}$ is associated with increasing PSA levels. However, when we stratified the population into 4 groups of increasing TZV quartiles, the PCa risk was decreased at the same PSA levels because of the inverse association between TZV and PCa. Patients presenting with the same PSA level of $5 \mathrm{ng} / \mathrm{ml}$ might show different probabilities of PCa by TZV measurements. PCa risk is about 0.10 in group 4, close to 0.30 in group 3 , about 0.45 in group 2, and just above 0.60 in group 1. As a result, the model stratifies the risk of detecting $\mathrm{PCa}$ in the different groups having the same PSA levels.

In a patient population undergoing a first random biopsy set, the study showed that TZV was associated with a decreased risk of $\mathrm{PCa}$.

PCa clinical models including age and PSA stratified by TZV quartiles were proposed (fig. 2 and 3). The proposed models might have potential applications in clinical practice when patients undergo a first random biopsy set. The subject dealing with associations between CII and $\mathrm{PCa}$ is controversial. However, the results of the present study confirmed an inverse association between $\mathrm{CII}$ and $\mathrm{PCa}$, which has been reported in clinical studies [6-8, 13-16]. It was also shown that baseline prostate inflammation is associated with a reduced risk of $\mathrm{PCa}$ in men undergoing repeat prostate biopsies [17].

In the present investigation, TZV was an independent predictor of both CII (direct association) and PCa risk (inverse association). The evidence of our study stresses the importance of evaluating the volume of the prostate according to the evolving zonal anatomy, which depends

Curr Urol 2017;11:85-91 
on aging and hormonal variations of total testosterone and oestrogens $[18,19]$.

There are limits in our study. First, it was a single center study, but the sample size was large enough. Second, we measured PV by means of TRUS and not by prostatectomy specimens. However; TRUS is widely used and it is considered an effective technique. Third, the inverse association of chronic inflammation with $\mathrm{PCa}$ might be confounded by PSA. PSA may be elevated by both inflammation and cancer, and hence, if biopsies are performed in cases with increased PSA, some patients will have cancer and others CII [20-22]. Patients with inflammation may undergo biopsy procedures more readily than men without inflammation because of potential higher PSA levels. As a result, men with CII will automatically be less likely to have cancer and vice versa. However, beyond the limits and because of the inclusion criteria, we are confident that our study gives evidence of the independent associations of CII and PCa when related to TZV.

\section{Conclusion}

In a patient population undergoing a first random prostate biopsy set because of suspected cancer, independent associations were detected among TZV, CII, and PCa. The association between TZV and CII was direct, but the relation between TZV and PCa was inverse. The

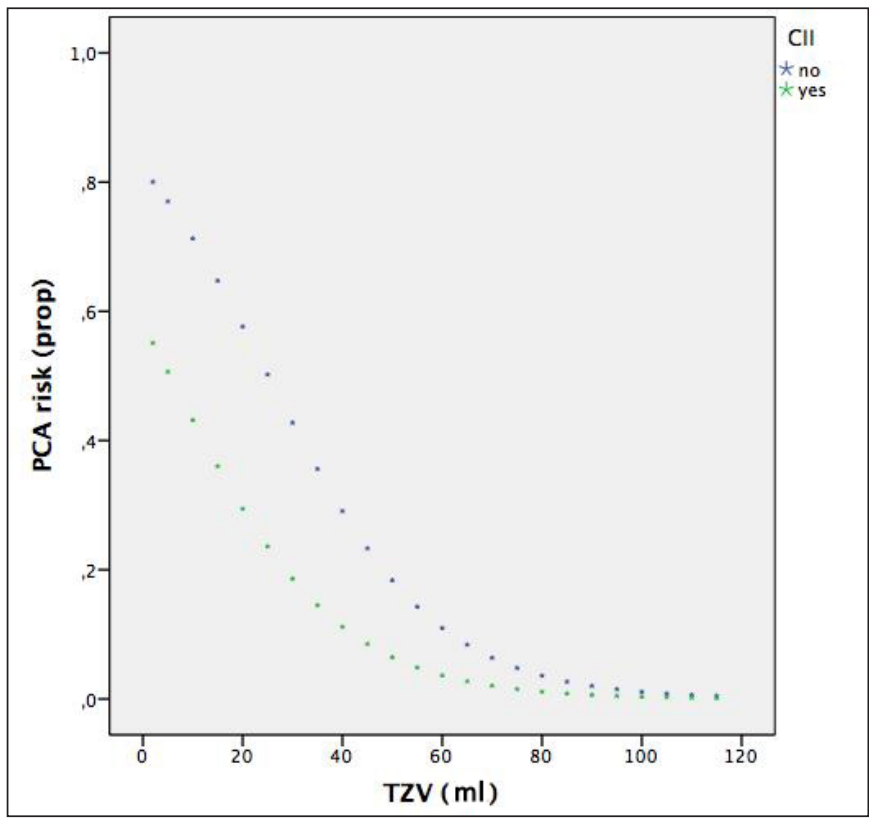

Fig. 4. The diagram illustrates the independent relations among $\mathrm{PCa}, \mathrm{TZV}$, and intraprostatic CII. The risk of detecting $\mathrm{PCa}$ is decreased by both TZV and intraprostatic CII.

measurement of TZV is a useful parameter for evaluating chronic intraprostatic inflammation and PCa risk. Our study outlines the importance of evaluation of the prostate according to the zonal anatomy of the gland.

\section{References}

1 Selman SH: The McNeal prostate: a review. Urology 2011;78:1224-1228.

2 De Nunzio C, Kramer G, Marberger M, Montironi R, Nelson W, Schröder F, Sciarra A, Tubaro A: The controversial relationship between benign prostatic hyperplasia and prostate cancer: the role of inflammation. Eur Urol 2011;60:106-117.

3 Gandaglia G, Briganti A, Gontero P, Mondaini N, Novara G, Salonia A, Sciarra A, Montorsi F: The role of chronic inflammation in the pathogenesis and progression of benign prostatic hyperplasia (BPH). BJU Int 2013; 112:432-441.
4 Krieger JN, Nyberg L Jr, Nickel JC: NIH consensus definition and classification of prostatitis. JAMA 1999;282:263-267.

5 De Marzo AM, Marchi VL, Epstein JI, Nelson WG: Proliferative inflammatory atrophy of the prostate: implications for prostatic carcinogenesis. Am J Pathol. 1999;155:19851992.

6 Blumenfeld W, Tucci S, Narayan P: Incidental lymphocytic prostatitis. Selective involvement with nonmalignant glands. Am J Surg Pathol 1992;16:975-981.
7 Porcaro AB, Novella G, Molinari A, Terrin A, Minja A, De Marco V, Martignoni G, Brunelli M, Cerruto MA, Curti P, Cavalleri S, Artibani W: Prostate volume index and chronic inflammation of the prostate type IV with respect to the risk of prostate cancer. Urol Int 2015;94:270-285.

8 Porcaro AB, Rubilotta E, Petrozziello A, Ghimenton C, Migliorini F, Zecchini Antoniolli S, La Cola V, Monaco C, Curti P, Cavalleri S, Pianon R, Artibani W: Chronic inflammation of the prostate type IV with respect to risk of prostate cancer. Arch Ital Urol Androl 2014; 86:208-211. 
9 Porcaro AB, Novella G, Cacciamani G, De Marchi D, Corsi P, De Luyk N, Bizzotto L, Processali T, Cerasuolo M, Tamanini I, Cerruto MA, Brunelli M, Siracusano S, Artibani W: Prostate volume index associates with a decreased risk of prostate cancer: results of a large cohort of patients elected to a first biopsy set. Urol Int 2017;98:22-27.

10 Epstein JI, Allsbrook WC Jr, Amin MB, Egevad LL: The 2005 International Society of Urological Pathology (ISUP) consensus conference on Gleason grading of prostatic carcinoma. Am J Surg Pathol 2005;29:1228-1242.

11 Pierorazio PM, Walsh PC, Partin AW, Epstein JI: Prognostic Gleason grade grouping: data based on the modified Gleason scoring system. BJU Int 2013;111:753-760.

12 Epstein JI, Zelefsky MJ, Sjoberg DD, nelson JB, Egevad L, Magi-Galluzzi C, Vickers AJ, Parwani AV, Reuter VE, Fine SW, Eastham JA, Wiklund P, Han m, Reddy CA, Ciezki JP, Nyberg T, Klein EA: A contemporary prostate cancer grading system: a validated alternative to the Gleason score. Eur Urol 2016; 69:428-435.
13 Gerstenbluth RE, Seftel AD, Maclennan GT, Rao RN, Corty EW, Ferguson K, Resnick MI: Distribution of chronic prostatitis in radical prostatectomy specimens with up-regulation of bcl-2 in areas of inflammation. J Urol 2002;167:2267-2270.

14 Irani J, Goujon JM, Ragni E, Peyrat L, Hubert J, Saint F, Mottet N: High-grade inflammation in prostate as a prognostic factor for biochemical recurrence after radical prostatectomy. Pathologist Multi Center Study Group. Urology 1999;54:467-472.

15 Karakiewicz PI, Benayoun S, Begin LR, Duclos A, Valiquette L, McCormack M, Bénard F, Saad F, Perrotte P: Chronic inflammation is negatively associated with prostate cancer and high-grade prostatic intraepithelial neoplasia on needle biopsy. Int J Clin Pract 2007; 61:425-430.

16 Zhang W, Sesterhenn IA, Connelly RR, Mostofi FK, Moul JW: Inflammatory infiltrate (prostatitis) in whole mounted radical prostatectomy specimens from black and white patients is not an etiology for radical difference in prostate specific antigen. J Urol 2000;163:131-136.
17 Moreira DM, Nickel JC, Gerber L, Muller RL, Andriole GL, Castro-Santamaria R, Freedland SJ: Baseline prostate inflammation is associated with a reduced risk of prostate cancer in men undergoing repeat prostate biopsy: results from the REDUCE study. Cancer 2014;120:190-196.

18 Palapattu GS, Sutcliffe S, Bastian PJ, Platz EA, De Marzo AM, Isaacs WB, Nelson WG: Prostate carcinogenesis and inflammation: emerging insights. Carcinogenesis 2005;26: 1170-1181.

19 Singh PB, Matanhelia SS, Martin FL: A potential paradox in prostate adenocarcinoma progression: oestrogen as the initiating driver. Eur J Cancer 2008;44:928-936.

20 Hoekx L, Jeuris W, Van Marck E, Wyndaele JJ: Elevated serum prostate specific antigen (PSA) related to asymptomatic prostatic inflammation. Acta Urol Bel 1998;66:1-2.

21 Sindhwani P, Wilson CM: Prostatis and serum prostate-specific antigen. Curr Urol Rep 2005;6:307-312.

22 Hochreiter WW: The issue of elevated prostate cancer evaluation in men with elevated prostate-specific antigen and chronic prostatitis. Andrologia 2008;40:130-133. 